\title{
MUNDIALIZAÇÃO FINANCEIRA E EDUCAÇÃO: OS IMPACTOS DAS POLÍTICAS NEOLIBERAIS NO ENSINO SUPERIO, O CASO DO BRASIL E CHILE
}

\author{
Aline Cristina Paiva ${ }^{1}$
}

\begin{abstract}
RESUMO: o presente trabalho trata de apresentar uma análise teórica sobre os impactos que as políticas neoliberais, direcionadas para educação, causaram nas instituições de ensino superior no Brasil e no Chile. A escolha por estes países deve-se ao fato de que, o primeiro passou por duas fases de mudanças políticas governamentais (governo FHC 1994-2002 e governo Lula 2003-2010) as quais implementaram, de modo diferente, as políticas educacionais nesse período. No governo FHC, as políticas neoliberais tinham um caráter mais ortodoxo se comparado ao governo Lula. O Chile, por outro lado, foi o precursor das políticas neoliberais implementadas na América Latina e mesmo com a crise do Estado neoliberal, ainda se caracteriza por ser um dos países que possui fortes influências neoliberais. Este estudo parte da análise dos documentos que foram produzidos após o Consenso de Washington, responsáveis pelas normas, as quais os países latino-americanos deveriam obedecer. Seguindo essa diretriz, também será analisado o papel dos organismos internacionais, no caso em foco, o Banco Mundial na intervenção do direcionamento que os países, neste caso: Brasil e Chile deveriam agregar à educação.
\end{abstract}

Palavras-Chave: Políticas. Neoliberalismo. Educação. Ensino Superior.

\section{FINANCIAL GLOBALIZATION AND A EDUCATION: THE IMPACTS OF POLICIES NEOLIBERAL IN HIGHER EDUCATION, THE CASE OF BRASIL AND CHILE}

\begin{abstract}
This work is to present a theoretical analysis on the impacts that neoliberal policies towards education, caused in higher education institutions in Brazil and Chile. The choice of these countries is due to the fact that the first left two phases of government policy changes (government Fernando Henrique Cardoso ,1994-2002 and government Luis Inácio Lula da Silva , 2003-2010) that implemented differently policies education in this period, since the Fernando Henrique Cardoso government, neoliberal policies had a more orthodox nature compared to Luis Inácio Lula da Silva. Chile, on the other hand, was the forerunner of the neoliberal policies implemented in latin-america, and despite the crisis of the neoliberal State, is still characterized as one of the countries appears as strong neoliberal tears. This study of the analysis of the documents that were made after the washington consensus, responsible for standards by which latin american countries should obey.in this sense, also Will analyze the role of internation organizations, as the World Bank and IMF, the

\footnotetext{
${ }^{1}$ Mestranda pelo Programa de Pós-Graduação Interdisciplinar Stricto Sensu em Sociedade, Cultura e Fronteiras na Universidade Estadual do Oeste do Paraná. Universidade Estadual do Oeste do Paraná. Email: acpaiva2000@yahoo.com.br
} 


\section{Atinerarius Revista Eletrônica da Pós-Gráduação

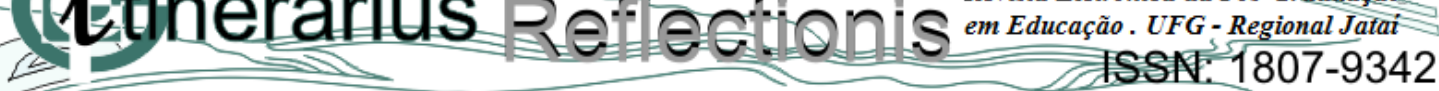 \\ v. 11, n. 2,2015}

intervention of the direction that cauntries, in this case, Brasil and Chile, should give to education.

Keywords: Policies. Neoliberalism. Education. Higher education.

\section{INTRODUÇÃO}

O presente artigo busca apresentar as transformações da educação de nível superior nos países, Brasil e Chile após a adoção das políticas de ajustes estruturais neoliberais. Em um primeiro momento é abordado o contexto pelo qual surgiu o neoliberalismo, nesse sentido é traçado um breve histórico que data do liberalismo econômico do século XVII e suas influências no neoliberalismo atual. Na segunda parte, buscou-se elencar os principais impactos das políticas neoliberais no Brasil, a começar pelo governo de Fernando Henrique Cardoso (FHC) até a fase do governo Lula. Nesse sentido, são apresentadas as principais mudanças ocasionadas pela adoção das propostas deliberadas pelos organismos internacionais, tendo como um dos focos principais o Ensino Superior, sobretudo a função exercida pelo Banco Mundial, criado após a Segunda Guerra (1939-1945), encarregado de promover a estabilidade do sistema financeiro internacional. Em seguida, é apresentado o caso chileno, que foi um dos países precursores da América Latina a aderir aos ajustes estruturais, sendo considerado um caso especial por ser um dos países da região que aplicou de modo ortodoxo as políticas neoliberais, (VERGARA 1984).

Após a análise dos impactos das políticas de ajustes neoliberais nos dois países estudados, apresentamos os aspectos comuns que afetaram as políticas educacionais para o ensino superior.

\section{HISTÓRICO DO NEOLIBERALISMO}

\subsection{Laissez faire, laissez passer}

O neoliberalismo foi inspirado no liberalismo econômico clássico do século XVII e XVIII, iniciado pelas ideias de Jonh Locke (1632-1704) e posteriormente Adam Smith (1723-1790), que rejeitaram as práticas mercantilistas, onde o Estado controlava toda a dinâmica econômica da nação (ANDERSON, 1996). Nessa nova perspectiva, a função que o Estado passa a exercer é o de garantir a livre concorrência, onde a economia é governada por uma mão invisível que, em momentos de crise, se autorregula por meio do movimento de 
oferta e procura. No século XVII, na escola dos fisiocratas, surge a primeira corrente do pensamento econômico, cuja frase Laissez faire, laissez passer, que significa "deixa fazer deixa passar", ficou conhecida por identificar o liberalismo (CADERNO nº5).

Na segunda metade do século XX, após a Segunda Guerra, o mundo sofria as consequências de um sistema falido. Percebe-se então, a necessidade de mudar os planos políticos e econômicos, uma vez que, já não era mais possível deixar a economia por si só regular as forças do mercado, haja vista, que as consequências da crise foram devastadoras para os Estados e empresas privadas, principalmente, para as classes menos favorecidas.

Através das propostas do então renomado economista inglês Jonh Keynes, o Estado diante da crise; após o crash da bolsa de valores de 1929; passou a participar das decisões econômicas, além de intervir no campo social. As políticas que foram aplicadas a partir das concepções keyneisianas ${ }^{2}$ deram ao Estado o caráter de Estado de bem-estar social, que conforme o historiador Maximiliano Martin Vicente (2009), caracterizou-se por ser uma tentativa de restaurar a economia dos países capitalistas,

O Estado de bem-estar social era um projeto cogente para recuperar o vigor e a capacidade de expansão dos países capitalistas após a tensão social, econômica e política do período entre guerras. Tanto que o estabelecimento do Estado de bemestar social, entre as décadas de 1940 e 1960, ficou conhecido como "era dourada do capitalismo" por ser um momento de desenvolvimento econômico, com garantias sociais e oferecimento, praticamente, de emprego pleno para a maioria da população nos países mais desenvolvidos. (VICENTE, 2009, p.124).

Com o surgimento da crise dos anos 70, a teoria Keyneisiana entrou em colapso, pois o Estado já não era capaz de evitar as novas crises. As consequiências levaram os países a tomarem medidas de desregulamentação da economia, privatizações e destituição do Estado de bem-estar social. Nesse contexto, nasce o chamado neoliberalismo, neo, que significa novo e liberalismo referente ao pensamento clássico, que serviu de base ao capitalismo.

\footnotetext{
${ }^{2} \mathrm{O}$ pensamento de Keynes reflete um momento de profunda crise do sistema capitalista. Sua teoria econômica é basicamente uma teoria monetária da produção que incorpora a ação estatal como mecanismo de estabilização de uma economia essencialmente instável, tendente ao desemprego e a crises cíclicas. A crise que atravessava o capitalismo em seu tempo representava, para o autor, o fim de uma visão harmônica e auto regulável de um sistema que tendia espontânea e automaticamente para o equilíbrio de pleno emprego. ( CORAZZA, 1985, p. 77)
} 


\title{
Atinerariuls Revista Eletrônica da Pös-Graduação

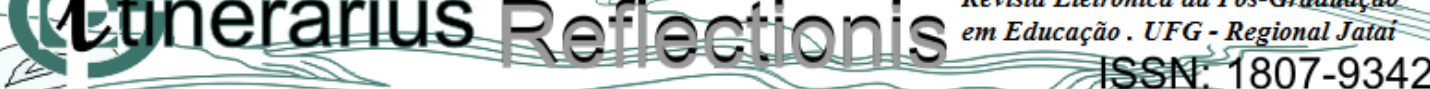 v. 11, n. 2,2015
} r

\subsection{NEO $=$ Novo liberalismo?}

Segundo Anderson (1996, p.9), "o neoliberalismo nasceu logo depois da II Segunda Guerra Mundial, como uma reação teórica e política veemente contra o Estado intervencionista e de bem-estar”. Dentre os economistas a influenciar as políticas neoliberais, encontra-se Friedrich Hayek, que em seu livro "Caminhos da Servidão”, publicado pela primeira vez em 1944, já condenava a intervenção do Estado na economia.

\begin{abstract}
Resgatando o liberalismo utilitarista de John Stuart Mill, Hayek defende o que chama de "Regime da Lei", como limite para a intervenção do governo na sociedade. Sob esse regime, "o governo limita-se a fixar regras determinando as condições em que podem ser usados os recursos disponíveis e deixando aos indivíduos a decisão sobre os fins a que esse serão aplicados. (HAYEK, 1946, p. 116 apud MORAES, p. 02).
\end{abstract}

Em 1947, Hayek convocou uma reunião na Suíça com célebres participantes, que também rejeitavam as políticas do Estado de bem-estar. Dentre os partícipes encontravam-se, Milton Friedman, Karl Popper, Lionel Robbins, dentre outros. Na ocasião deste encontro, as idéias desses liberais foram pouco consideradas, o que muda completamente na década de 1973, quando a crise tomou proporções mais agudas fazendo com que as proposições de Hayek e seus seguidores fossem revistas e aplicadas (ANDERSON, 1996). Nesse sentido, a solução para a crise seria

(...) manter um Estado forte, sim, em sua capacidade de romper o poder dos sindicatos e no controle do dinheiro, mas parco em todos os gastos sociais e nas intervenções econômica (...). As reformas fiscais eram imprescindíveis, para incentivar os agentes econômicos. Em outras palavras isso significava reduções de impostos sobre os rendimentos mais altos e sobre as rendas. (ANDERSON, 1996, p.10-11)

Um dos pioneiros na adoção das políticas neoliberais foi o Chile, durante a ditadura do general Augusto Pinochet nos anos 70. Segundo Anderson (1996, p.19), "o Chile começou seus programas de maneira dura: desregulação, desemprego massivo, repressão sindical, redistribuição de renda em favor dos ricos, privatização de bens públicos". Cabe sublinhar, que os países que lideraram de fato os ajustes neoliberais, foram os Estados 
Unidos, no governo Reagan (1981-1989) e a Inglaterra de Margaret Thatcher, que governou de 1979 a 1990.

Na América Latina, os efeitos da crise levaram os países a adotarem os ajustes neoliberais orientados, principalmente, pelo Banco Mundial (BM), Fundo Monetário Internacional (FMI), Banco Internacional de Reconstrução e Desenvolvimento (BIRD) e o governo dos Estados Unidos, logo após o "Consenso de Washington” ${ }^{3}$. Conforme Pilar Vergara (1984), os impactos de tais ajustes não se materializaram apenas no campo econômico, mas atingiram outros setores como o campo das reformas educacionais, da saúde e do trabalho.

Segundo Jaime Estay (2007), houve um aumento notável da taxa de desemprego. Ao analisar os dados da Comissão Econômica para a América Latina e o Caribe (CEPAL), o autor citou os seguintes dados referentes à taxa de desempregos: de 6,9\% no início dos anos de 1990 para 10,0\% em 2004, esse aumento, escreve Estay (2007), esteve acompanhado do crescimento dos setores informais:

\begin{abstract}
Este aumento del desempleo estuvo acompañado por un ascenso de la informalidad, que implicó que, durante La última década, el $70 \%$ del aumento del empleo haya estado concentrado en los sectores informales, a la vez que más del $63 \%$ de los miembros activos Del $40 \%$ de las familias más pobres de la región trabajan actualmente en el sector informal, y dedican la totalidad de sus ingresos laborales a subsistir. (CEPAL, 2005, p.7 apud ESTAY, 2007, p.208).
\end{abstract}

No que se refere ao número de pessoas em situação de pobreza, houve um aumento significativo: de 136 milhões em 1980, para 222 milhões em 2004 (ESTAY, 2007). Conforme dados da CEPAL (1991 apud SOARES, 2000), o panorama social da América Latina durante a década de 1980 foi marcado pelas seguintes características:

-Distribuiu-se menos equitativamente uma renda per capita que foi menor na maioria dos países da região;

\footnotetext{
${ }^{3}$ Em novembro de 1989, reuniram-se na capital dos Estados Unidos funcionários do governo norte-americano e dos organismos financeiros internacionais ali sediados - FMI, Banco Mundial e BID - especializados em assuntos latino-americanos. O objetivo do encontro, convocado pelo Institute for International Economics, sob o título "Latin American Adjustment: How Much Has Happened?", era proceder a uma avaliação das reformas econômicas empreendidas nos países da região. Para relatara experiência de seus países também estiveram presentes diversos economistas latino-americanos. Às conclusões dessa reunião é que se daria, subseqüentemente, a denominação informal de "Consenso de Washington". (BATISTA, 1994, p. 5)
} 


\begin{abstract}
-Na maioria dos casos, os 5\% mais ricos viram manter-se ou aumenta seus ingressos, enquanto os $75 \%$ mais pobres viram-se diante da redução dos seus ingressos, agudizando-se o contraste entre bem-estar e pobreza;

-Apesar da expansão educativa, América Latina ainda não conseguiu que uma importante proporção da sua população alcance os níveis educacionais requeridos por aquelas ocupações que geram níveis aceitáveis de produtividade;

-Os jovens que não estudam nem trabalham constituem atualmente uma proporção maior que ao princípio da década. Esta situação, que afeta principalmente àqueles pertencentes à famílias de baixa renda, é um indicador do risco de marginalidade e de reprodução de famílias com elevada vulnerabilidade econômica e social. (TAVARES, 2000, p.31-32).
\end{abstract}

Para Campos e Soares (2014), a taxa de crescimento baixo, somados ao modelo de acumulação neoliberal, comprovou ser um ótimo mecanismo para aumentar a pobreza na América Latina. Nesse sentido, o discurso neoliberal entra em crise, pois os dados indicam que houve um retrocesso nas condições de melhoria de vida da população e em 2008, com a explosão da crise financeira, que começou nos Estados Unidos e se espalhou pelo resto do mundo, mais uma prova surgiu de que o mercado não se regula por si só.

\title{
3. NEOLIBERALISMO E EDUCAÇÃO
}

\subsection{A retórica dos liberais}

Pablo Gentili (1994) aponta que o neoliberalismo não é apenas um conjunto de estratégias políticas, econômicas e jurídicas com a finalidade de solucionar a crise do capital que teve seu início ao final dos anos 60, mas também, é a expressão de um projeto de reforma ideológica. Desse modo, os governos neoliberais, juntamente com os organismos multilaterais, não apenas conseguem colocar em ação seu programa de ajustes, mas sugerem que a adesão é a única saída possível. Os intelectuais neoliberais reconheceram que a construção de um senso comum, era uma das metas a serem alcançadas para garantir o sucesso de uma ordem social pautada no livre-mercado e sem a intervenção estatal.

Segundo Gentili (1994) o discurso dos neoliberais acerca da reforma educacional, pauta-se sobre a crise de eficiência, eficácia e produtividade. A premissa neoliberal alega que a rápida expansão das escolas no século passado, foi feita sem a necessária eficiência na distribuição dos serviços oferecidos. Essa expansão desordenada leva a falta de qualidade decorrente da má gestão administrativa e da falta de competências nas práticas pedagógicas. Para os neoliberais, as escolas não sofrem uma crise de democratização, mas uma crise 


\section{Atinerariuls Revista Eletrốnica da Pós-Graduação

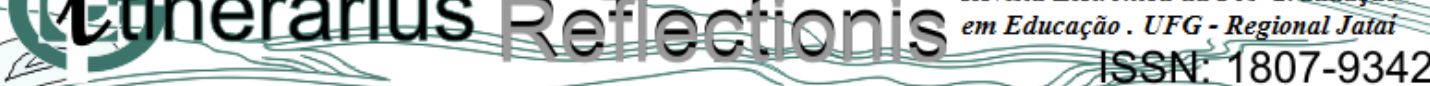 \\ v. 11, n. 2,2015}

gerencial. "Esta crise promove, em determinados contextos, certos mecanismos de "iniquidade" escolar, tais como a evasão, a repetência, o analfabetismo funcional etc". (GENTILI, 1994, p. 17).

Nesse caso, a retórica construída pelos neoliberais fundamenta-se na falta de qualidade e eficiência das escolas em gerir seus recursos, para eles, não há falta de escolas, mas sim de escolas melhores, assim como não falta professores, mas professores qualificados. Nessa lógica, a culpa pela ineficiência das políticas públicas educacionais recai sobre o Estado, que segundo os neoliberais, é o responsável pela crise que leva a evasão, a repetência e as elevadas taxas de analfabetos funcionais. O problema está na ausência de um mercado educacional. Nas palavras de Gentili (1994),

Só esse mercado, cujo dinamismo e flexibilidade expressam o avesso de um sistema escolar rígido e incapaz, pode promover os mecanismos fundamentais que garantem a eficiência dos serviços oferecidos: a competição interna e o desenvolvimento de um sistema de prêmios e castigos com base no mérito e no esforço individual dos atores envolvidos na atividade educacional. Não existe mercado sem concorrência, sendo ela o pré-requisito fundamental para garantir aquilo que os neoliberais chamam de equidade. (GENTILI, 1994, p.19).

Para Olgaíses Maúes (2003), essas reformas possuem objetivos políticos pontuais, que abrangem a estrutura administrativa e pedagógica da escola, bem como, a formação docente, além dos aportes teóricos e dos conteúdos a serem ensinados. No modelo pedagógico neoliberal, não há espaço para setores como o sindicato docente ou mesmo para as associações de pais e alunos serem ativos no processo de construção do modelo de educação que contemple a realidade específica de cada país e região destes Estados. "La nueva conduccíon de la educacíon latinoamericana estaba definida; los sujetos determinantes de la política académica y curricular eran directamente lãs fuerzas econômicas" (PUIGGRÓS, 1996, p. 7).

Na construção desse consenso, encontram-se os organismos internacionais, dentre eles, o Banco Mundial, que exerceu um importante papel nas estratégias de "melhoria" da qualidade da educação. O Grupo Banco Mundial foi criado em 1944, trata-se de uma agência financeira multilateral, composta por cinco agências: Banco Internacional para a Reconstrução e o Desenvolvimento (BIRD, 1944), Corporação Financeira Internacional (CFI, 1956), Agência Internacional de Desenvolvimento (AID, 1960), Agência de Garantia de 
Investimentos Multilaterais (MIGA, 1960) e Centro Internacional para a Resolução de Disputas sobre Investimentos (IGSID, 1962). O Banco foi criado por iniciativa norteamericana, no contexto do pós-guerra, cuja finalidade era emprestar crédito aos governos para o desenvolvimento de seus países, mediante projetos de infraestrutura, (BERNUSSI, 2014). Cada instituição que compõe o Banco, dentro de sua funcionalidade, é capaz de angariar recursos em outras fontes do mercado mundial para fornecer créditos. Segundo dados do site ${ }^{4}$ oficial do BM, o Banco é composto por 188 países sócios que age como um estratégico financiador de projetos para o setor público e privado. A partir dos anos de 1970, o Banco passou a exercer uma função importante no que se refere ao financiamento para o setor social, atuando como monitorador dos ajustes estruturais junto aos países-membros (FONSECA, 1997).

Conforme Adriana Puiggrós (1996), as imposições econômicas que essas organizações financeiras determinam para o setor educacional, acaba interferindo desde os salários dos professores até nas mudanças estruturais do sistema e nas reformas dos conteúdos. Para a autora, foram justamente estas ingerências que sucateou o sistema educativo em vários países da América Latina, sendo perceptíveis, sobretudo, nos anos de 1990 e nas primeiras décadas do século XXI.

Os organismos internacionais coisificam e subsumem o conhecimento como componente estratégico de geração e incremento da riqueza (sociedade do conhecimento). Nessa ótica, as universidades devem se associar às empresas e aos setores empresariais, e os docentes devem ser meros empreendedores, configurando a mercantilização do conhecimento. Como os países periféricos e semiperiféricos são capitalistas dependentes e marcados pela heteronomia cultural, a venda de serviços afasta a universidade do rigor teórico e da vigilância epistemológica e, sobretudo, dos grandes problemas nacionais. (ANDES-SN, 2005).

\section{ESTUDO DE CASO}

\subsection{O caso do Brasil}

O governo de Fernando Henrique Cardoso (1994-2002) e de Luis Inácio Lula da Silva (2003-2010) transformou significativamente o ensino superior brasileiro. No governo

\footnotetext{
${ }^{4}$ The World Bank < http://www.worldbank.org/pt/country/brazil >
} 
FHC, as políticas de ajustes neoliberais foram aprofundadas, tendo as seguintes características:

\begin{abstract}
A implementação de ajustes estruturais e setoriais empreendidos no Brasil, tais como o Plano Real, o ajuste fiscal do governo federal, estaduais e municipais, a privatização de empresas estatais, a reforma previdenciária, a reforma administrativa e do Estado, a reforma trabalhista, tributária, a reforma da educação básica, profissional e superior, a reforma do judiciário e, ainda, tendo como uma prioridade setorial de longo prazo: educação básica ao promover as reformas educacionais, respondem aos interesses dominantes internos e externos. (DEITOS, 2005, p.210219)
\end{abstract}

Segundo Lima (2005), a educação é vista no governo FHC como um serviço público não estatal, pautada na inserção dos indivíduos no ensino superior com a finalidade de inseri-los no mercado de trabalho e na garantia do desenvolvimento do país. Um estudo sobre o "Desenvolvimento da Educação no Brasil”, realizado pelo Ministério da Educação em 1996, já indicava alguns problemas nesse nível de ensino, como o pouco número de vagas oferecidas. Desse modo, os investimentos dos setores privados no âmbito educacional ganharam um notório papel. Conforme Sguissard (2008), o número de instituições privadas cresceu $127,8 \%$. No que se refere ao número de matrículas, o mesmo autor aponta que no octênio de 1994- 2002, as matrículas no ensino superior público foram de 52,3\% e no ensino privado de $150,2 \%$. Isso implica dizer que,

\begin{abstract}
O governo FHC inicia um processo de direcionamento do mercado educacional e de indução das políticas públicas dos estados e municípios através de exames centralizados. A criação do Provão para o ensino superior é um exemplo desta política, que abre mão de uma atuação efetiva do Estado ao mesmo tempo em que inicia a construção de um modelo competitivo em consonância com a lógica dos interesses privados. (VALENTE-SN 2009).
\end{abstract}

Em decorrência dessas políticas, o ensino superior passou por um período de deterioração. Isso se deu a partir dos cortes de verbas, da não abertura de concursos públicos para professores e funcionários técnico-administrativos. Além disso, houve uma expansão de matrículas para os setores privados, em detrimento da destinação das verbas públicas para as faculdades particulares, pelo significativo crescimento das fundações privadas, além de não haver avanços nas políticas de assistência estudantil (FIGUEIREDO, 2005). Um dos projetos 


\section{Mtineroriulo Revista Eletrônica dâ Pós-Graduação v. 11, n. 2,2015}

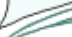

que marcaram o processo de desmantelamento do ensino superior público, foi o projeto de autonomia de 1995 do Ministério da Administração e da Reforma do Estado (MARE). Que, conforme Carvalho (2007) consistiu em:

(...) transformar o status jurídico das universidades públicas para organizações sociais, entidades públicas não estatais, fundações de direito privado ou sociedades civis sem fins lucrativos. A interação entre o Estado e estas organizações sociais se daria, por meio de um contrato de gestão, no qual estariam previstos os serviços que seriam prestados, as metas a serem atingidas e os recursos financeiros que deveriam ser transferidos a cada ano, do governo para a organização. (CARVALHO, 2007, p. $3-4)$.

Seguindo esse projeto, o então Ministro da Educação, Paulo Renato de Souza, apresentou no ano de 1996, os três pilares para reforma universitária, sob a orientação do Banco Mundial:

a) Avaliação Institucional e Exame Nacional de Cursos (Provão);

b) Autonomia Universitária;

c) Melhoria do Ensino, através do Programa de Gratificação e estímulo à Docência/GED. (FIGUEIREDO-SN, 2005).

Tais diretrizes marcam a consolidação das propostas neoliberais, e como já foi mencionado aqui, consolidam as políticas de privatização das Universidades, tirando assim a responsabilidade do Estado frente ao fomento e financiamento da educação.

Quanto ao governo Lula (2002-2010), no que se refere às políticas para o setor privado do ensino superior, o programa de governo priorizou a manutenção das instituições existentes, dando-lhes condições de permanência, ao invés de seguir com o aumento dessas. (CARVALHO, 2007). Desse modo, o novo governo dá continuidade às recomendações do Banco Mundial, especialmente com a criação do PROUNI (Programa Universidades para Todos), que consiste em conceder bolsas de estudos integrais e parciais, em instituições privadas para alunos que estudaram em escolas públicas ou que tiveram bolsas integrais. $\mathrm{O}$ discurso é de justiça social, mas ao mesmo tempo, foi uma das soluções para preencher as vagas ociosas, atendendo as pressões feitas pela iniciativa privada. (LUCHMANN, 2007).

No que se refere ao governo Lula, apesar das mudanças no programa de reformas para o ensino superior, as propostas neoliberais permaneceram, conforme as características apresentadas por Arantes (2006, p.04): 
Legalização das fundações privadas nas universidades, através da sua regulamentação (Decreto $\mathrm{N}^{\mathrm{o}}$ 5.205/2004); b) Estímulo à ampliação das parcerias e convênios com as instituições privadas; c) As Parcerias Público Privado que permitem a destinação de verbas públicas para a iniciativa privada e desta para o setor público; d) O Projeto de Lei de Inovação Tecnológica, que repassa a responsabilidade de produção de conhecimento para o setor privado; e) O Programa Universidade para Todos - ProUni (MP No 213), que regulamenta a "compra" das vagas ociosas nas universidades particulares, destinando desta forma verba pública para salvar os empresários deste setor; f) O Projeto de Emenda Constitucional (PEC 217) da Deputada Selma Schons (PT-PR) que prevê a cobrança de impostos a ex-alunos de universidades públicas; e g) O Sistema Nacional de Avaliação do Ensino Superior - SINAES (Lei N ${ }^{o} 10.861$, de 14 de Abril de 2004), que pouco difere do antigo "Provão", mantendo a utilização de critérios burocráticos e meritocrático e o ranckeamento dos curso.

Apesar da continuidade das políticas neoliberais no governo Lula, quando comparadas ao governo de FHC, percebe-se que houve uma tentativa de amenizar os impactos que os ajustes estruturais causaram sobre o ensino superior,

Em linhas gerais, em contraste com as recomendações do BIRD e a ação política do governo anterior - a educação superior como um serviço comercializado no mercado - destaca-se nos três anteprojetos a função social da educação superior, e, a partir da segunda versão a definição explícita de bem público, mantendo a gratuidade do ensino em estabelecimentos oficiais. (CARVALHO, 2007, p.10).

Diante desses dados, é possível afirmar que, embora o governo FHC tenha sido marcado por um período onde, os ajustes estruturais foram perversos no âmbito educacional, o governo Lula não deixou de lado tais políticas, pois suas medidas indicaram a continuidade, ainda que menos perceptíveis dos tais ajustes.

\subsection{Educação Superior no Chile nos marcos do neoliberalismo}

O Chile é considerado um dos primeiros países na implementação das políticas neoliberais sob o regime militar. A partir de 1981 houve grandes transformações no Ensino Superior. O contexto em que o Chile aderiu ao receituário neoliberal foi marcado pela forte repressão da ditadura, o que proibia as manifestações por parte de estudantes contrários às novas políticas de ajustes estruturais, além do forte controle sobre os conteúdos a serem ensinado. 


$$
\text { v. } 11, \text { n. } 2,2015
$$

\begin{abstract}
Os años 80 en Chile se inician, así, con sangre y reformas. Ambos asuntos marcarían a prácticamente todos lo ámbitos de la vida del país. Uno de los aspectos más radicalmente intervenidos y que por lo mismo se vuelve paradigmático, es el de la Educación Superior. Entre 1980- 1981 el gobierno militar dicta una serie de "Decretos con fuerza de ley" que se dieron en llamar Nueva Ley de Universidades. En dicha normativa legal se vienen a concretar cambios que ya se venían operando hace algunos años y que cristalizan definitivamente en estos años adquiriendo una institucionalización vigente en su mayor parte hasta hoy mismo, luego de quince años del retorno de la democracia .(HERCEG,2006p,06).
\end{abstract}

Desse modo, a conjuntura política, econômica e social do Chile, acabou sendo “favorável” para execução dos ajustes estruturais no âmbito da educação, sob orientação dos organismos internacionais. As principais medidas realizadas conforme Inzunza (2011) foram:

a) Prioridade para o investimento na educação primária e secundária, deixando a margem os investimentos para o Ensino Superior.

b) A redução dos gastos para o Ensino Superior, que chegara a 50\%;

c) Criação de várias instituições de nível superior, sem o controle estatal.

Segundo Brunner (2008 apud INZUNZA, 2011), a característica principal do sistema educacional chileno pode resumir-se na existência de,

a) un mercado de consumidores donde se paga un arancel - sea a través de becas o créditos- para acceder al servicio educativo;

b) un mercado laboral de posiciones académicas con una baja regulación en el caso privado, y con mayores para las instituciones estatales que contratan y despiden a sus profesores, fijan su escala salarial y regulan la carrera del personal académico;

c) un mercado de prestigios institucionales donde se asocia la calidad y la selección de los mejores estudiantes en determinadas instituciones. (BRUNNER apud INZUNZA, 2011, p. 07).

Uma das principais características do ensino superior chileno é a privatização, o que começou aos finais da década de 1970 e início dos 80, ainda permanece. Ruiz Encina (2013) cita a Ley General de Universidades de 1981, que separou as universidades de suas sedes, dando autonomias a estas últimas, anulando assim o caráter nacional da Universidade do Chile, dando início ao fomento da privatização e da criação de instituições privadas. Para Diáz (2005, p. 56) "A efetivação das propostas da reforma gerou duas novas categorias de classificação institucional: universidades "derivadas" e universidades "privadas.

Segundo Cabalin (2013), apesar da reforma ter possibilitado o aumento do número de estudantes no ensino superior, a qualidade não seguiu o movimento de ampliação, 


\title{
Prineroriulo Revista Eletrônica da Pös-Graduação ¿

para o autor, a desigualdade no campo educativo aumentou em todos os níveis, do pré-escolar ao ensino superior.

Las políticas neoliberales han permitido que algunas universidades sean un negocio multimillonario, donde los estudiantes son vistos como clientes que pagan caros aranceles y asumen créditos casi impagables.Los Estudiantes chilenos em 2011 protestaron contra esta estructura, pero esta movilización no hubiera sido posible sin los esfuerzos innovadores de La "Revolucíon de los Pinguinos 5 años antes.(CABALIN, 2013,p.8-9).

As conseqüências dessa onda privatista foram evidenciadas a partir de 2006, com a chamada "Revolta dos Pingüins", quando estudantes do ensino médio organizaram inúmeras passeatas e manifestações em prol de medidas de melhorias para a educação. Em abril de 2011, milhares de estudantes protestaram na capital chilena, em oposição ao alto custo da educação superior e por conseqüência, ao crescente endividamento dos estudantes, explica Mario Garcés (2012). As paralisações dos setores, públicos e privados nesse período chegou a durar, sete meses. A educação chilena, na atualidade, é a mais cara do mundo, apontou o relatório da Organização de Cooperação e de Desenvolvimento Econômico (OCDE) de 2011, citado por Mayol (et.al, 2011,p.13),

\begin{abstract}
A nivel de la educación superior, es la más cara del mundo: según el último ranking de la OCDE, los aranceles universitarios que paga el alumno en nuestro país son más del doble que en Estados Unidos, 3 veces México, 5 veces España, 18 veces Francia, sin contar aquellos países donde las universidades son gratuitas, vale decir Argentina y Brasil, en Sudamérica, y la mayor parte de los países de Europa. (MAYOL, et, al, 2011,p.13)
\end{abstract}

Lara Antonia Alvares e Natalia Monzón Montebello (2013) chamam atenção para os fundos de financiamentos criados pelo governo chileno, para que os estudantes pudessem arcar com as mensalidades, haja vista que, o ensino superior é praticamente privatizado e caro. Desse modo, o governo criou o "Fundo Solidário de Crédito Universitário, programa de crédito a juros baixos e prazos longos para alunos de baixa renda, definindo assim a característica do subsídio para a educação superior por meio de empréstimos bancário" (ALVARES e MONTEBELLO, 2013, p.5).

Desse modo, é possível perceber que mesmo com a chegada dos governos democráticos, o incentivo ao setor privado seguiu crescendo. Segundo dados coletados pelo 
órgão informativo do Movimento Estudantil Popular Revolucionário (MEPR) de 2011, o Estado chileno contribui apenas com $20 \%$ das receitas para manutenção das principais universidades do país. "Mesmo em universidades públicas as cobranças de matrículas chegam ao equivalente a 12 mil reais anuais. O governo do Chile gasta apenas cerca de 0,6\% do PIB com ensino superior público" (MEPR, 2011, p. 3).

\section{ALGUNS APONTAMENTOS}

\subsection{A educação neoliberal no Brasil e Chile}

Diante do que foi exposto, sobre as principais consequiências das políticas de ajustes estruturais neoliberais no ensino superior brasileiro e chileno, foi possível constatar que ambos passaram pelas mesmas propostas objetivadas pelos organismos internacionais. Principalmente pelo Banco Mundial. No entanto, como foi apresentado, o Brasil, além de ter entrado de modo tardio na dinâmica dos ajustes neoliberais, os meios pelos quais se deu o esse processo, não foi ortodoxo se comparado ao caso chileno.

O Brasil de 1994 a 2006 passou por duas importantes reformas no ensino superior, tendo como origem a Lei de Diretrizes e Bases da Educação Nacional (LDB/96). Nesse contexto, o mercado da educação entra em cena com as privatizações e o crescimento das instituições privadas. Na segunda fase, já no governo Lula, houve uma redução dos setores privados na educação, contudo, as políticas que já estavam presentes no governo FHC continuaram, apesar de que, o governo Lula trouxe uma melhora no que diz respeito ao aumento das instituições federais, ampliando assim o número de vagas; criou o Programa Universidade para Todos (PROUNI), que concede bolsas de estudos integrais e parciais em instituições privadas, e ampliou o Exame Nacional do Ensino Médio (ENEM), da era FHC, tornando-o um dos indicadores de qualidade da educação.

Tanto no Brasil quanto no Chile, é questionável esses indicadores de qualidade, pois são orientados pelos organismos internacionais e privados, bem como o sistema de créditos e financiamento presentes no Chile e no Brasil. No Chile, a partir do Fundo Solidário, os estudantes passaram a individar-se, segundo Katz (2011, apud Vasconcelos, 2015), cerca de $40 \%$ dos estudantes não podem pagar suas dívidas. No Brasil, o Fundo de Financiamento 


\section{Mrineraríls Revista Eletrônica da Pós-Graduação

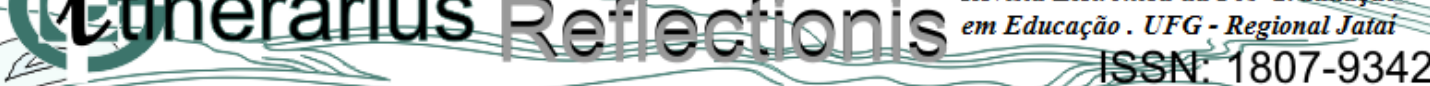 \\ v. 11, n. 2,2015}

Estudantil (FIES), criado em $1999^{5}$, também é um fator que pode levar o estudante ao endividamento. Segundo dados do Censo do Ensino Superior de 2007, 10, 7\% dos estudantes que usam a verba do FIES, não pagam a dívida. Entretanto, o MEC considera aceitável essa taxa devido à extensão do programa. Para Viviane Queiroz (2015, p.53), esse processo de ampliação da "Educação Superior no setor privado ocorre historicamente em nosso país, sob a aparência de ampliação do acesso, atendendo aos interesses da burguesia brasileira e internacional".

O problema da interferência dos setores privados na educação é justificado pelo fato de que estes não estão preocupados com as especificidades de cada país, nem com as demandas e as fragilidades do campo educacional, que são produto de um processo histórico. O que ocorre é a subserviência ao mercado e aos interesses dos empresários. Se no período colonial havia a imposição de uma educação eurocêntrica, hoje não é diferente, só muda o nome dos "novos colonizadores" e seus representantes. Neste trabalho foi apresentado um deles: o Banco Mundial, contudo, é só um dos organismos internacionais aos quais, países como o Brasil e o Chile devem se distanciar e passar a propor soluções e direções que condizem com sua a realidade política, econômica e social. Vale ressaltar que o Estado também foi responsável pela implementação das políticas neoliberais, uma vez que disse sim ao "Consenso de Washington", desse modo, soma-se uma conjuntura de fatores atrelada a questões internas e externas que atendem os interesses do capital.

\section{REFERÊNCIAS BIBLIOGRÁFICAS}

ALVARES, Lara Antonia. MONTEBELLO, Natalia Monzón. O Movimento estudantil de 2011 e a crise de legitimidade do sistema político chinelo. In: Seminário de Iniciação Científica da ESPM, 2 , 30 e 31 out. 2013, São Paulo. Anais... São Paulo: ESPM, 2013. Disponível em: http://www2.espm.br/sites/default/files/pagina/lara_antonia_alvares__ii_semic_2013_0.pdf >. Acesso em: 13 mar. 2014.

\footnotetext{
${ }^{55}$ A partir da Lei. $n^{\circ} 11.552 / 2007$, o FIES foi ampliado. No governo Lula e no da atual presidenta Dilma Rousseff o programa brasileiro de financiamento estudantil passou abarcar os programas de mestrado, doutorado e os cursos técnicos. (QUEIROZ, 2015).
} 
ANDES. Ensino Público e Gratuito: Direito de Todos, Dever do Estado. Agenda para a Educação Superior: uma proposta do ANDES-SN para o Brasil de hoje. Disponível em: <http://www.fedepsp.org.br/superior/agenda_andes.pdf>. Acesso em: 24 mar. 2014.

ANDERSON, Perry. Balanço do neoliberalismo. In: SADER, Emir; GENTILI, Pablo (Org.). Pós-neoliberalismo: as políticas sociais e o Estado democrático. 3 ed. Rio de Janeiro: Paz e Terra, 1996.

ARANTES. Adriana. Políticas Educacionais no Brasil: Visão geral da Educação Superior. Goiás. 2006. Disponível em < http://www.catolicadeanapolis.com.br/portal/uploads/files/834c77ce96f6953f4348fd56cc07db c8.pdf. Acesso em 24/03/2014. Acesso em: 23/09/2014.

BATISTA, Paulo. O Consenso de Washington: a visão neoliberal dos problemas latino-americanos. In: BATISTA, Paulo (et al.). Em defesa do interesse nacional: desinformação e alienação do patrimônio público. Rio de Janeiro: Paz e Terra, 1994.

BERNUSSI, Mariana Medeiros. Instituições Internacionais e Educação: A agenda do Banco Mundial e do Education For All no caso Brasileiro. 2014.101 f. Dissertação Mestrado em Relações Internacionais). Universidade de São Paulo, São Paulo. 2014.

BRASIL. Ministério da Educação. Plano de Desenvolvimento da Educação: razões, princípios e programas. Brasília: MEC, 1996.

Brasília: 1996.

. Senado Federal. Lei de Diretrizes e Bases da Educação Nacional: nº 9394/96.

CABALIN, Cristian. La Disputa por la Educación en Chile: Neoliberalismo y

Movimientos Estudiantiles. In: Congreso la Asociación de Estudios Latinoamericanos, Washington, mai/jun.2013. Anais... Disponível em:<

https://www.academia.edu/3653113/La_disputa_por_la_educaci\%C3\%B3n_en_Chile_Neolib eralismo_y_movimientos_estudiantiles > Acesso em 13 abril. 2014.

CADERNO $\mathrm{n}^{\circ}$ 5. O Neoliberalismo ou o mecanismo para fabricar mais pobres entre os pobres. 2. ed. Consulta Popular: SP, 2000.

CARVALHO, Cristina Helena. Política para o ensino superior no Brasil (1995-2006): ruptura e continuidade nas relações entre público e privado. $26^{\mathrm{a}}$ Reunião Anual da ANPED, Caxambu, MG. 20 maio. 2012, Anais... Disponível : < www.anped.org.br/reunioes/29ra/trabalhos/trabaho/GT11-2337--Int.pdf. Acesso em: 14 abril. 2014.

CENSO do ensino superior 2007. MEC/INEP. Disponível em:< http://download.inep.gov.br/download/superior/censo/2007/Resumo_tecnico_2007.pdf >. Acesso em 15. Mai.2014. 
CEPAL. 2002. Globalização e Desenvolvimento. Brasília. Comissão Econômica para a América Latina. Disponível em < www.eclac.org > Acesso: 10 mar.2014.

CORAZZA, Gentil. Teoria Econômica e Estado. De Quesnay a Keynes. 114 f. Tese (Doutorado em economia). Porto Alegre, Universidade Federal do Rio Grande do Sul, 1985.

DEITOS, Roberto Antônio. O capital financeiro no Brasil. 394 f. Tese (Doutorado em Educação). Campinas, Universidade Estadual de Campinas, 2005.

DÍAZ. Sebastían Danoso. A reforma neoliberal da educação superior no Chile em 1981. Revista Brasileira de Ciências Sociais. v.20, n.57, São Paulo, Fev. 2005. Disponível em: < http://www.scielo.br/scielo.php?script=sci_arttext\&pid=S0102-69092005000100004. Acesso em : 21 abril. 2014.p.53-204

ENCINA, Juiz. Conflicto social en el neoloberalismo avanzado: Analise de clase de La revuelta estudiantil em Chile. Buenos Aires: Clacso, 2013.

FIGUEIREDO. Erika. Reforma do Ensino Superior no Brasil: um olhar a partir da história. Revista da UFG, Goiás, v.7, n.2, dez. 2005. Disponível em: < http://www.proec.ufg.br/revista_ufg/45anos/C-reforma.html. Acesso em 23/03/2014. Acesso em : 15 mai.2014.

FONSECA, Marília. O Banco Mundial e a Gestão da educação brasileira. In: Gestão democrática da educação: desafios contemporâneos. Dalila Andrade de Oliveira (Org.). Petrópolis-RJ: $4^{\text {a }}$ Ed. Vozes, 1997.

GARCÉS, Mario. EI despertar de la sociedad. Los movimientos sociales em América Latina y Caribe. Santiago: LOM Ediciones, 2012.

GENTILI, Pablo A.O discurso da qualidade como nova retórica conservadora no campo educacional. In: GENTILI, Pablo A. A. e SILVA, Tomás T. da. Neoliberalismo, qualidade total e educação: visões críticas. 5 ed., Petrópolis: Vozes, 1994.

HERCEG. José. Anomalias del modelo neoliberal em Chile. Estudios Avanzados Interactivos, Santiago, v.5, n.7. 2006. Disponível em:< http://web.usach.cl/revistaidea/html/revista\%207/pdf/santos.pdf $>$. Acesso em: 24 abril.2014.

INZUNZA. Jorge. La educación Chilena: Custionamientos al Neoliberalismo. Revista Remo. Ed. Especial, out. 2011. Disponível em < http://www.remo.ws/REVISTAS/remodigital.pdf>. Acesso em 21 mar.2014.p.6-10.

LIMA. Kátia Regina Rodrigues. A reforma do Estado e da educação no governo Fernando Henrique Cardoso: o ENEM como mecanismo de consolidação da reforma. $249 \mathrm{f}$. Tese ( (Doutorado em Educação). São Carlos: UFSCar, 2005. 


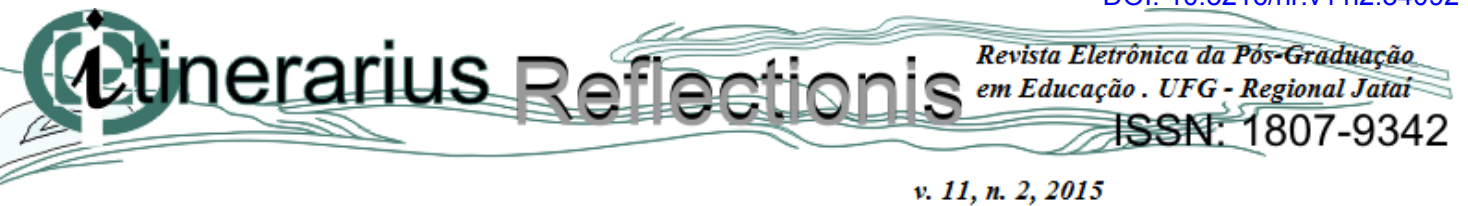

LÜCHMANN, Lígia Helena. A representação no interior das experiências de participação. Revista de Cultura e Política, São Paulo, n.70. 2007.p.139-170.

MAÚES, Olgaíses. Reformas internacionais da educação e formação de professores. Cadernos de pesquisa. São Paulo, n.118. Disponível: < http://www.fcc.org.br/pesquisa/publicacoes/eae/arquivos/1532/1532.pdf . Acesso em 15 abril. 2014.

MAYOL, Alberto. El derrumbe del modelo. La crisis de la economía de mercado en el Chile contemporâneo. Santiago: Ciencias Humanas. 2013.

MORAES. Antônio. Mito do Estado mínimo. Lutas Sociais. São Paulo. v.1, n.1 Nov. 1996. Disponível em <http://www.pucsp.br/neils/downloads/v1_artigo_moraes.pdf >. Acesso em: 22 abril. 2014.

OCDE. Informe sobre las políticas educaciónales en Chile. Santiago. 2003.

PUIGGRÓS, Adriana Educación neoliberal y quiebre educativo. Nueva Sociedad.n.146, Nov-Dez. 1996. Disponível em: < http://nuso.org/media/articles/downloads/2549_1.pdf > Acesso em: 21 abril. 2014.

QUEIROZ, Viviane de. Fundo de Financiamento Estudantil (FIES): uma nova versão do CREDUC. Universidade e Sociedade (Brasília), v. 55, 2015. p. 44-57,

SGUISSARDI, Valdemar. Modelo de expansão da educação superior no Brasil: predomínio privado/mercantil e desafios para a regulação e a formação universitária. Educ. Soc., Campinas, v. 29, n. 105, dez. 2008. Disponível em < http://www.scielo.br/pdf/es/v29n105/v29n105a04.pdf > Acesso em 25 abril. 2014. p.9911022.

ESTAY, Jaime. La inserción de América Latina em el actual orden internacional: crisis y alternativas. In: GAMBINA, Julio. ESTAY, Jaime (Orgs), Hacia dónde va el sistema mundial? Impactos y alternativas para América Latina y El Caribe. Buenos Aires: Fund. Investigaciones Sociales y Políticas - FISyP. 2007.

SOARES. Laura. Os custos do ajuste neoliberal na América Latina. São Paulo: Cortez Editora, 2000.

SOARES, Rosana; CAMPOS, Christiane. Neoliberalismo e dependência na América Latina. Espacio Abierto, v. 23, n. 1, p. 45-70. jan/mar .2014

VALENTE. Ivan. Educação não é mercadoria. Disponível em < http://www.ivanvalente.com.br/wpcontent/uploads/2010/03/Caderno_Educa\%C3\%A7\%C3\% A3o.pdf. Acesso em: 23 mar. 2014. 


\section{Ptinerariuls Revista Eletrônica da Pós-Graduação

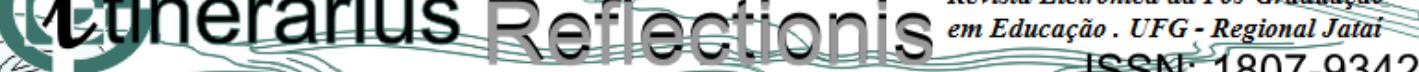 \\ v. 11, n. 2,2015}

VASCONCELOS, Joana Salém. O que resta da ditadura no Chile. 2015. In: Colóquio Marx e o Marxismo 2015: Insurreições, passado e presente. 2015. Niteroí. Anais...Niteroí, 2015.Disponível em < http://www.niepmarx.com.br/MM2015/anais2015/mc20/Tc201.pdf > Acesso em : 01 set.2015.

VERGARA Pilar. Auge y caída del neoliberalismo en Chile. Santiago: FLACSO, 1984. 